\title{
Game-Based Learning (GBL) in Mechanical Engineering Education: Case Study of GBL Application in Computer Aided Design (CAD) Assembly
}

Mr Mike Mavromihales

Senior Lecturer and Course Leader, School of Computing and Engineering, University of Huddersfield, West Yorkshire, UK, HD1 3DH

Email: m.mavromihales@hud.ac.uk

Dr Violeta Holmes

Subject Area Leader, School of Computing and Engineering, University of Huddersfield, West Yorkshire, UK, HD1 3DH

Email: v.holmes@hud.ac.uk

Dr Radu Racasan

Senior Lecturer, School of Computing and Engineering, University of Huddersfield, West Yorkshire, UK, $H D 13 D H$

Email: r.racasan@hud.ac.uk 


\title{
Game-Based Learning (GBL) in Mechanical Engineering Education: Case Study of GBL Application in Computer Aided Design (CAD) Assembly
}

Mike Mavromihales, Email: M.mavromihales@hud.ac.uk

Violeta Holmes, Email: v.holmes@hud.ac.uk

Radu Racasan, Email: r.racasan@hud.ac.uk

\begin{abstract}
In our research we aim to evaluate the effectiveness of Games-based learning (GBL) within a Computer Aided Design and Manufacture (CAD/CAM) undergraduate module. Although widely used in a selection of subject areas, there appears to be limited application of GBL in Engineering and Technology (E\&T). Its effectiveness as a learning or training tool, especially in Mechanical Engineering subject area, has been unclear. This research follows on from previously presented research in novel approaches in delivery of engineering education. Games-based Learning has a potential to enhance student experience and learning process. In order to evaluate the outcomes of GBL approach and observe its effect on students' performance, a simple in-class game on assembly topics was designed and implemented as part of a laboratory exercise. There were two groups of students' considered in this case study: the student group "playing" an assembly game (experimental group) and the group which did not experience GBL (control group). The results of the assessment element in the experimental group were compared to the control group. Our work evaluates both the qualitative and quantitative data established from CAD assembly delivery using the game, and delivery using conventional method. In addition, the comparisons were made between the entry level in to Higher Education in terms of tariff points level (academic score) of participants and educational background. It thus concludes on the effectiveness of the Games-based learning process in Mechanical Engineering Education.
\end{abstract}

Keywords: Game-based learning (GBL); Game design; Motivated learning; Group collaboration in learning 


\section{Introduction}

Games-based learning (GBL) has been widely used in a selection of subject areas within the Higher Education (HE) sector, especially Business. There has been a significant rise in published work on the subject of gamification to enhance engineering teaching and learning during the last seven years [Hamari $\mathrm{J}$ et al 2014, Seaborn K and Fels DI 2015]. Despite the significant rise of research in this area and the positive effect in engineering education, there appears to be a distinct lack of empirical surveys [Markopoulos et al 2015] and quantitative analysis for the value of gamification effects [Kim S, 2013]. In Engineering and Technology (E\&T), its effectiveness as a learning or training tool, especially in this subject area appears to be largely unclear. Some research supports the view that GBL learning and attitudes towards it are rapidly changing. Therefore, the primary aim of this research is to evaluate the effectiveness of GBL within Mechanical Engineering specifically within a Computer Aided Design undergraduate module.

In order to evaluate the effectiveness of GBL a Resin Puzzle game was designed and integrated into a delivery of Computer Aided Design activity. In this paper we report on the outcomes of this investigation.

The Resin Puzzle game has been incorporated as part of an intermediate module (year 2 of engineering undergraduate study) on a BEng Mechanical Engineering course. The aim of the game is to partly fulfil the learning outcomes of a module in CAD/CAM. These are:

- To demonstrate an understanding of the various CAD/CAM technologies and the various categories of 3-D modelling systems, their application in industry (knowledge and understanding).

- Be capable of undertaking a variety of engineering design activities and design tasks on industry standard CAD systems (abilities).

- To demonstrate knowledge of individual elements of modern design concepts and methods (knowledge) 
- The students must also be able to identify key areas of design analysis (such as material selection) and choose appropriate methods for their solution in a considered manner (ability in cognitive and intellectual skill)

- Operate in a situation of varying complexity and predictability requiring the application of an appropriate technique of modern design (ability - practical skill)

- Select and use of a communication method appropriate to the product design analysis (a key transferable skill)

\subsection{Research questions}

There were a number of research questions to be addressed as part of this research in to GBL. There were,

- Is there a correlation between the students who performed in the higher finishing positions at the end of the gamification event and their end of year assessment element in assembly?

- How do absent students perform in their end of year assessment element in assembly compared with the students who take part in the gamification event?

- Do the students who performed in the higher finishing positions enter Higher Education with a greater number of tariff points compared to the lower finishing and non-completing students?

- How does the year group perform in comparison to the previous year's group were no such activity was incorporated in delivery?

Although the CAD system planned for this activity was Solidworks 3D CAD, the activity can be adapted for any 3D CAD system in order to achieve the learning outcomes.

The design of the resin game followed current guidelines supported by previous research.

\section{Game Development and Applied Pedagogy for Enhanced Game- Based Learning}

The game development for engineering education is challenging task.

Even if a game is built on sound pedagogical foundations and incorporates proven educational practices, if it is not fun or otherwise engaging, it will fail to meet expectations of both the developer and the end user. By contrast, if game design 
dominated the process such that the game primarily focused on entertainment, fun and winning, it may fail to apply key pedagogical principles and players, despite being entertained, may have left lacking in knowledge and not achieved any of the learning outcomes.

The danger lies in forcing perceived learning requirements and traditional teaching practices into the game thus disturbing the riveting interactions of gameplay.

A game may therefore easily distract players who may be enticed by the use of highend graphics and animation, or by competing, scoring and winning, rather than learning. Hiruni and Stapleton describe a systematic process for designing serious games that integrate common instructional systems design (ISD) tasks with a game development process to optimise game-based learning.

Hiruni and Stapleton put forward a case for instructional games to be applied at four levels in order to optimise learning. It is also suggested [Driscoll, 1994] that instruction may be viewed as a series of events that are intentionally designed to facilitate learning and achieve specified learning goals. In terms of educational games, at instructional event level 1 , for instance, the game may be designed to facilitate one specific instructional event within an instructional unit or lesson. An instructional game, for example, may be designed to facilitate recall of factual content or to promote active involvement and discussion [Demsey, Lucassen, Haynes \& Casey, 1996, Blake and Goodman, 1999]. At instructional event level 2 a game may address two or more events contained in an instructional unit. For instance, a game may present learners with a scenario to engage their interest and ask them to explore related concepts through a series of readings and activities. Additional events such as learner assessments and feedback, may have to occur before and/or after gameplay to facilitate learning. Such methodology appears to draw correlation to Bloom's Taxonomy [Bloom, 1964].

A framework that helps illustrate how the results of fundamental Instructional Design tasks may be used to facilitate the design of instructional games was proposed by Stapleton and Hughes [2006]. Key components in a game were proposed as follows: Story

- WHY should I care, from the player's point of view? 
Game

- HOW do things work (procedural or mechanics)?

Play

- WHAT am I doing (how do I participate)?

According to Hirumi and Stapleton

'By applying pedagogy and knowledge of the subject matter, learners, and instructional context to answer the questions, designers flesh out the core game plan and reconcile game and learning goals so that the entertainment supports the learning and the learning enhances the entertainment. The more the learning content and objectives are interwoven into the entertainment elements, the more the game will reinforce the learning objectives.'

Both Instructional Design (ID) and video game development (GD) processes consist of comparable phases. Table 1 below identifies key tasks associated with each phase of the ID process [Hirumi and Stapleton, 2010].

Table 1 - Applying Pedagogy during the Game Development Process - ID Process and Tasks [Hirumi and Stapleton, 2010].

\begin{tabular}{|c|c|}
\hline Analysis Phase & GD Process and Products \\
\hline $\begin{array}{l}\text { - Assess needs and identify goals(s) } \\
\text { - Analyse goal(s), learner and context }\end{array}$ & $\begin{array}{l}\text { - Prepare pitch document } \\
\text { - Prepare game concept } \\
\text { document }\end{array}$ \\
\hline Design Phase & Pre-Production Phase \\
\hline $\begin{array}{l}\text { - Generate, cluster and sequence } \\
\text { - objectives }\end{array}$ & $\begin{array}{l}\text { Create game design } \\
\text { documents }\end{array}$ \\
\hline - Determine learner assessment method & $\begin{array}{l}\text { - Prepare art bible and } \\
\text { production plan }\end{array}$ \\
\hline - Generate instructional strategy & $\begin{array}{l}\text { - Create technical design } \\
\text { document }\end{array}$ \\
\hline - Select media & \\
\hline Development Phase & Prototype and Production Phases \\
\hline $\begin{array}{l}\text { - Acquire materials or outsource } \\
\text { development }\end{array}$ & $\begin{array}{l}\text { Develop analog or low- } \\
\text { fidelity prototypes }\end{array}$ \\
\hline - Create flowcharts and storyboards & $\begin{array}{l}\text { Develop tangible } \\
\text { prototypes }\end{array}$ \\
\hline - Generate prototypes & - Produce Alpha Version \\
\hline $\begin{array}{l}\text { - Formatively evaluate and revise } \\
\text { material }\end{array}$ & - Produce Beta Version \\
\hline
\end{tabular}




\begin{tabular}{|c|c|}
\hline & $\bullet$ Produce Gold Version \\
\hline Implementation and Evaluation Phases & Post-Production \\
\hline$\bullet \quad$ Deliver and manage instruction & $\bullet \begin{array}{l}\text { Generate and release } \\
\text { subsequent versions }\end{array}$ \\
\hline $\begin{array}{l}\text { Plan and conduct summative } \\
\text { evaluations }\end{array}$ & $\begin{array}{l}\text { Generate and release } \\
\text { upgrades/expansions }\end{array}$ \\
\hline
\end{tabular}

Inevitably the tools, tasks and techniques used during each phase of game development may vary by project and/or subject area but the phases remain basically the same. It is important to note that the design of instructional games differs from entertaining games in that they are designed intentionally to facilitate achievement of specific learning goals and objectives. Application of pedagogy is necessary to facilitate achievement and optimise games-based learning. Hirumi and Stapleton make a strong case that pedagogy is necessary to facilitate achievement and optimise games-based learning. During the concept development, the selection of basic instructional support provides valuable insights into how content information is to be presented to learners.

Aamodt and Plaza [1994] identified that game based learning can be based on a one or more principles of learning (behavioural, cognitive information processing, constructivist learning or brain-based learning). They addressed the question as to whether games should apply a specific instructional strategy, model or theory, such as case-based reasoning, Learning by Doing [Schank, Berman \& Macpherson, 1999] or Problem-Based Learning [Barrows, 1985]. The selection and application of the instructional approach is critical as it ultimately affects the manner in which learners achieve specified learning outcomes.

For a constructivist approach to a game, a "story" may present learners with a scenario or problem and the "game play" may require learners to utilise various tools to access content information, derive meaning, and construct their own knowledge of how to work through a scenario and/or solve the problem. Details of how the game will apply key principles, tools and events associated with a particular approach need to be defined at an early 'pre-production' stage. By basing early entertainment development on pedagogy, further creative choices in the game development will tend to enhance achievement in learning objectives. 
Table 2 [Hirumi and Stapleton, 2010] outlines events associated with alternative instructional strategies which are based (or strongly linked to) learning and instructional research theory.

Table 2 - Primary Events Associated with Grounded Instructional Strategies [Hirumi and Stapleton, 2010]

\begin{tabular}{|c|c|c|}
\hline $\begin{array}{l}\text { Adaptive Instructional Design (Schwartz, Lin, } \\
\text { Brophy \& Bransford, 1992) }\end{array}$ & Collaborative Problem-Solving (Nelson, 1999) & Learning by Doing (Schank, Berman \& Macpherson, 1999) \\
\hline 1. Look Ahead and Reflect Back & 1. Build Readiness & 1. Define Goals \\
\hline 2. Present Initial Challenge & 2. Form and Norm Groups & 2. Set Mission \\
\hline 3. Generate Ideas & 3. Determine PreliminaryProblem & 3. Present Cover Story \\
\hline 4. Present Multiple Perspectives & 4. Define and Assign Roles & 4. Establish Roles \\
\hline 5. Research and Revise & 5. Engage in Problem Solving & 5. Operate Sceranios \\
\hline 6. Test your Mettle & 6. Finalise Solution & 6. Provide Resources \\
\hline 7. Go Public & 7. Synthesize and Reflect & 7. Provide Feedback \\
\hline 8. Progressive Deepening & 8. Assess Products and Processes & \\
\hline 9. Reflection and Decision Assessment & 9. Provide Closure & \\
\hline 5E Instructional Model (BSCS, 2006) & Problem-Based Learning (Barrows, 1985) & Case-Based Reasoning (Aamodt \& Plaza, 1994) \\
\hline 1. Engage & 1. Start NewClass & 1.Present New Case/Problem \\
\hline 2. Explore & 2. Start New Problem & 2. Retrieve Similar Cases \\
\hline 3. Explain & 3. Problem Follow-Up & 3. Reuse Information \\
\hline 4. Elaborate & 4. Performance Presentations & 4. Revise Proposed Solution \\
\hline 5. Evaluate & 5. After Conclusion of Problem & 5. Retain Useful Experiences \\
\hline Experiential Learning (Pfeiffer \& Jones, 1975) & Simulation Model (Joyce, Weil, \& Showers, 1992) & Constructivist Learning (Jonassen, 1999) \\
\hline 1. Experience & 1. Orientation & 1. Select Problem \\
\hline 2. Publish & 2. Participant Training & 2. Provide Related Cases \\
\hline 3. Process & 3. Simulation Operations & 3. Provide Information \\
\hline 4. Internalize & 4. Participant Debriefing & 4. Provide Cognitive Tools \\
\hline 5. Generalize & 5. Appraise and redesign the simulation & 5. Provide Conversation Tools \\
\hline 6. Apply & & 6. Provide Social Support \\
\hline
\end{tabular}

\section{Game Design - Educational Aims and Objectives}

The outcomes of literature review on Game design and applied pedagogy, were used to inform the design of GBL in Mechanical engineering.

The stages of Instructional Design were addressed, although not all in a formal manner - there were no formal pitch and game concept documents even though these issues were addressed. The intention was to arrive at a proposal that addressed the learning outcomes and evaluate after the event. A readily available 
prototype was used (the resin puzzle) as supplied by Protomold (www.protomold.eu/parts). This was identified as an ideally suitable artefact that met the requirements for the experimental event but could also be evaluated in terms of suitability in developing the gamification event further.

The game consists of a nine part Resin Puzzle Key. Figure 1 shows the nine parts of the puzzle and figure 2 shows the assembled puzzle. Each piece of the puzzle is made from a different polymer type and is colour coded accordingly. Each of polymers is more suited to certain design applications and one of the objectives of the game is for students to investigate material application and retain the information for questions addressed by the facilitator (cognitive recollection).

Learners were provided with instructions regarding the aims and objectives of the activity, the rules of the game and how it was to be conducted. Communication of the instructional approach would also assist in the future design and development of the gamification process. Learners were briefed on defined goals, learning objectives, operational instructions and rules of the game. They were thus able to gauge their own progress during the game.

Students should be paired within a class size of no more than 30 (15 maximum competing pairs) for the activity. The typical size was closer to half that. There were a total of six groups partaking in the game at different times during the period of a week. It is important to note here that students could not access the model files or the resin puzzle game outside the scheduled sessions. The first objective is to solve the puzzle in their allocated pairs by assembling the pieces following basic graphical instruction (Collaborative Problem Solving - Nelson, 1999). Graphical guidance to solving the puzzles is only provided following a lapse of time (15 minutes) in which to complete it. It is unusual for students to be able to solve the puzzle without basic illustrative guidance, yet a small number had achieved this showing good aptitude for practical and logical problem solving.

Students will be advised to remember the material of each piece of the puzzle and the associated colour. The colours help them to form a mental link to the type of polymer for investigation.

Learners will be observed as to how they are collaborating to solve the puzzle and timed accordingly. A display board will record the ranking order of completers and 
will score them according to their order of completing the puzzle. Extra points will be awarded for each repeated completed assembly, until time is called. The first part of the game is run for 40 minutes.

The next part of the game entails a virtual assembly of the puzzle using a $3 \mathrm{D}$ Computer Aided Design (CAD) Solid Modelling system. This part of the game is also time constrained. Students will be given access to the 3D Solid models of the individual puzzle parts to form a virtual assembly. This part of the game emulates the physical assembly completed prior but this time there will be no diagrammatic instructions as to how the parts are assembled and constrained. This should be completed based on memory (Learning by Doing - Schank, Berman \& Macpherson, 1999) and will highlight retention from the previous part of the game. In order to successfully complete this stage of the game students were required to draw on previous knowledge on SolidWorks assembly gained during the weeks leading to gaming activity. They were required to apply virtual manipulation skills and constrain the individual modelled pieces by judgement, visualisation, planning and methodical thinking. The range of 'mate' constraints required were not exhaustive as this would have distracted some students from the overall objectives of the game. Constraints such 'coincident' mate and 'width' mate in addition to part rotation for orientation would suffice for completing the virtual assembly. The build process would prove to be significantly easier provided that the pieces were assembled in a particular order which could be established during the physical build. The most successful students had already identified this before they arrived the virtual build stage. 


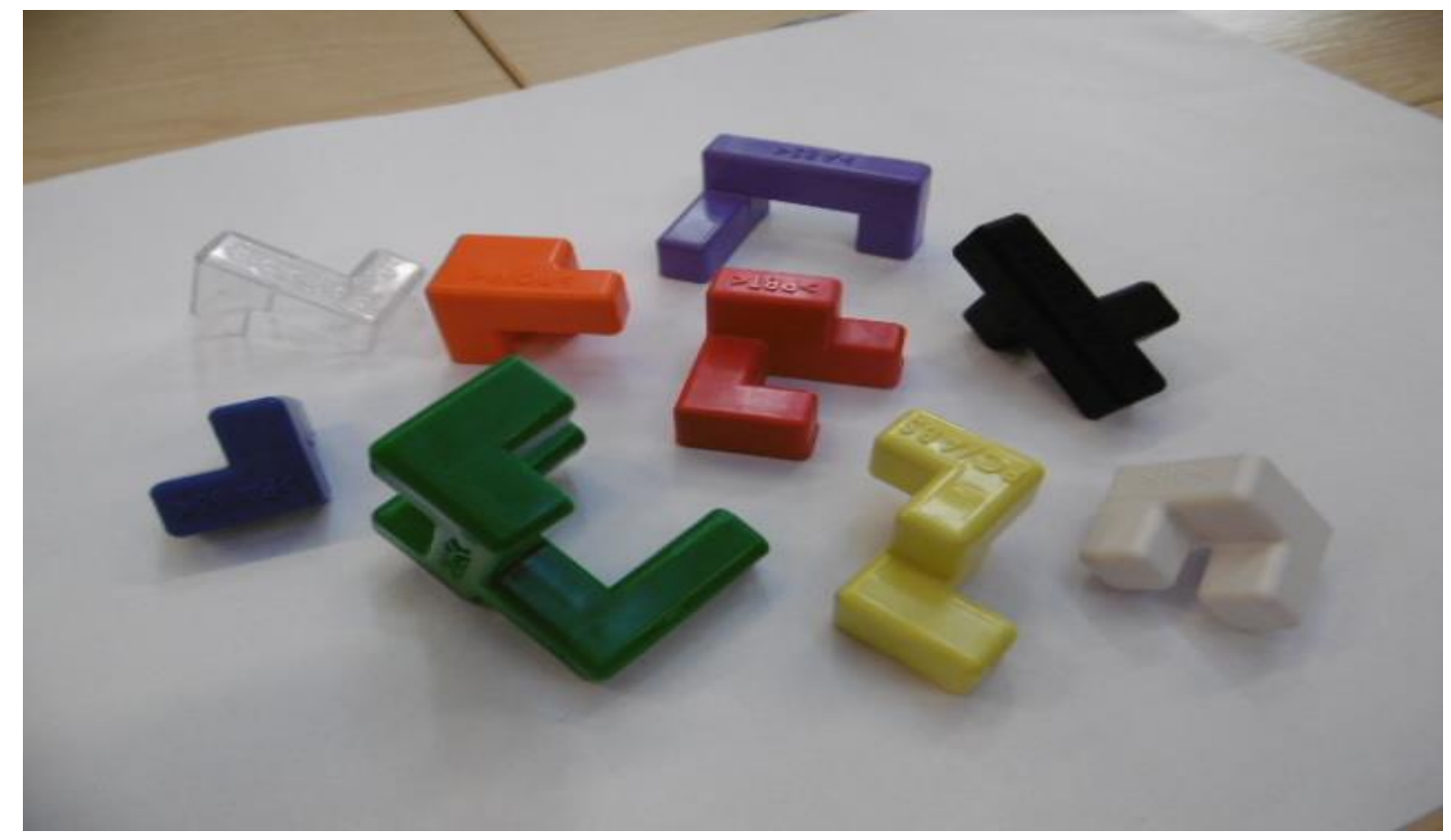

Figure 1 - The nine parts of the Resin Puzzle Key

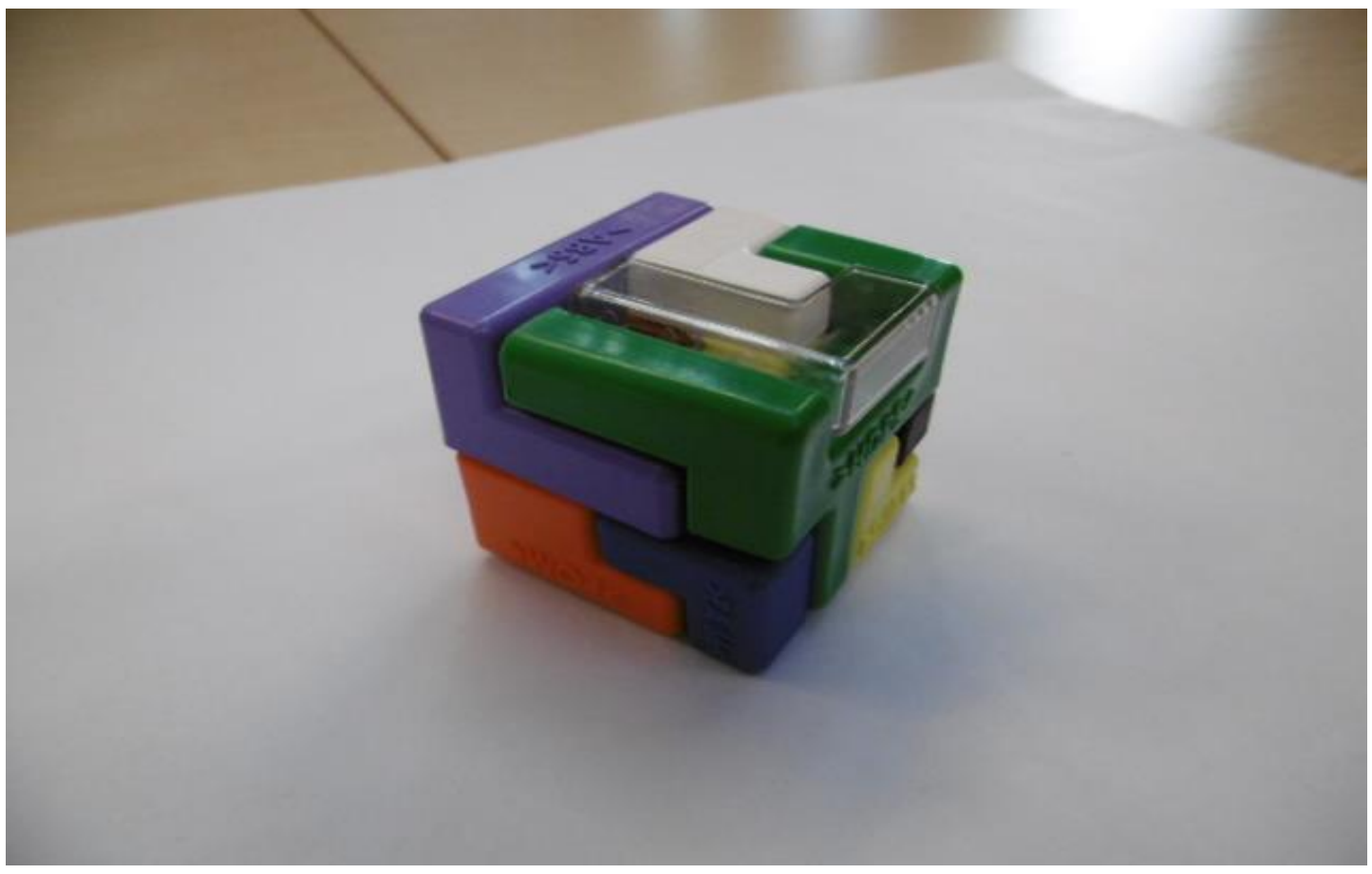

Figure 2 - The assembled Resin Puzzle Key 


\subsection{Learning pre-requisites}

Proficiency in the use of the 3D CAD modelling software, SolidWorks for assembly, is achieved through instruction and practice during the weeks prior to the activity using a range of different assemblies. Each student pair is required to contribute to the assembly build. Participants are observed while doing so. This helps resolve potential unfair advantage of having a particularly strong individual member in a pair working solo to complete the entire exercise. Collaboration is possible through partnership between pairs, providing a tool for conversation (Constructivist Learning and collaboration, Jonassen, 1999 and Nelson, 1999). As in the previous part of the game, a display board will be used to record the ranking order of completers and are scored accordingly.

Students are also expected to have the pre-requisite skills of searching for the information required in the quiz on materials properties for the plastics. Knowledge and recollection is not as important as the ability to source information. The important aspect of this part of the overall activity is to raise awareness of the availability of a range of engineering polymers available to engineering designers.

\subsection{Research questions and outcomes}

There were several questions that were posed during the development of the learning game activity. Guidelines for good practice in GBL were followed. The research questions to be addressed were aimed at establishing the following:

- Had the students applied the skills and knowledge gained in the sessions leading to the event and were skills further reinforced, partly through collaborative learning with their assigned partner during the activity?

- Which students had performed better and why? Is there a link to prior learning, attendance and qualifications at point of entry in to Higher Education?

- Had collaboration enhanced or hindered certain competitors and why?

- Did the activity serve as an effective means of formative self-assessment, to gauge standards of students against peers?

- Was the activity enjoyable as an alternative method of delivery? 
- Would the activity lead to improved performance in assessment?

- Was there a link between performance in manual and computer assembly?

\subsection{Game Based Activity Deployment}

The attendance for all the students during the weeks leading to the activity was recorded. We can therefore relate performance to attendance.

Each student had registered their presence and participation prior to the game. We considered this to be important in order to accurately monitor groups and the profile of participants. To have failed to maintain an accurate record of this, would have skewed the results of the experiment. The accurate tagging of participants was therefore important. Educational background information as well as recreational interests for each participant was available on record.

Research results analysis was based on comparisons between participants (experimental group) and non-participants (control group). The division of the groups for the experiment was based on two academic years (2015/16 and 2016/17). The students who were enrolled for the same module during the previous year had not taken part in the game but were assessed in exactly the same way at the end of year (first control group). The assessment was based on successful completion and understanding of a set of assembly exercises. Both the control groups and the experimental group had the same exercises to complete and assessed in exactly the same way. This was one-to-one questioning on assembly constraints based on the given exercises. An example of one of the exercises on which students were assessed at the end of year is shown in figure 3. As in similar examples students are individually questioned on applied constraints, editing individual parts for improved fit, limiting the range of movement of specific parts etc. The experiment was to establish whether the opportunity to reinforce key skills during the GBL event would allow the experimental group to score higher in assessment, given that both the control and experimental groups had identical assessed work.

The absent or non-participating students in the gaming event was incidental and also due to absence of part of the cohort (second control group). 


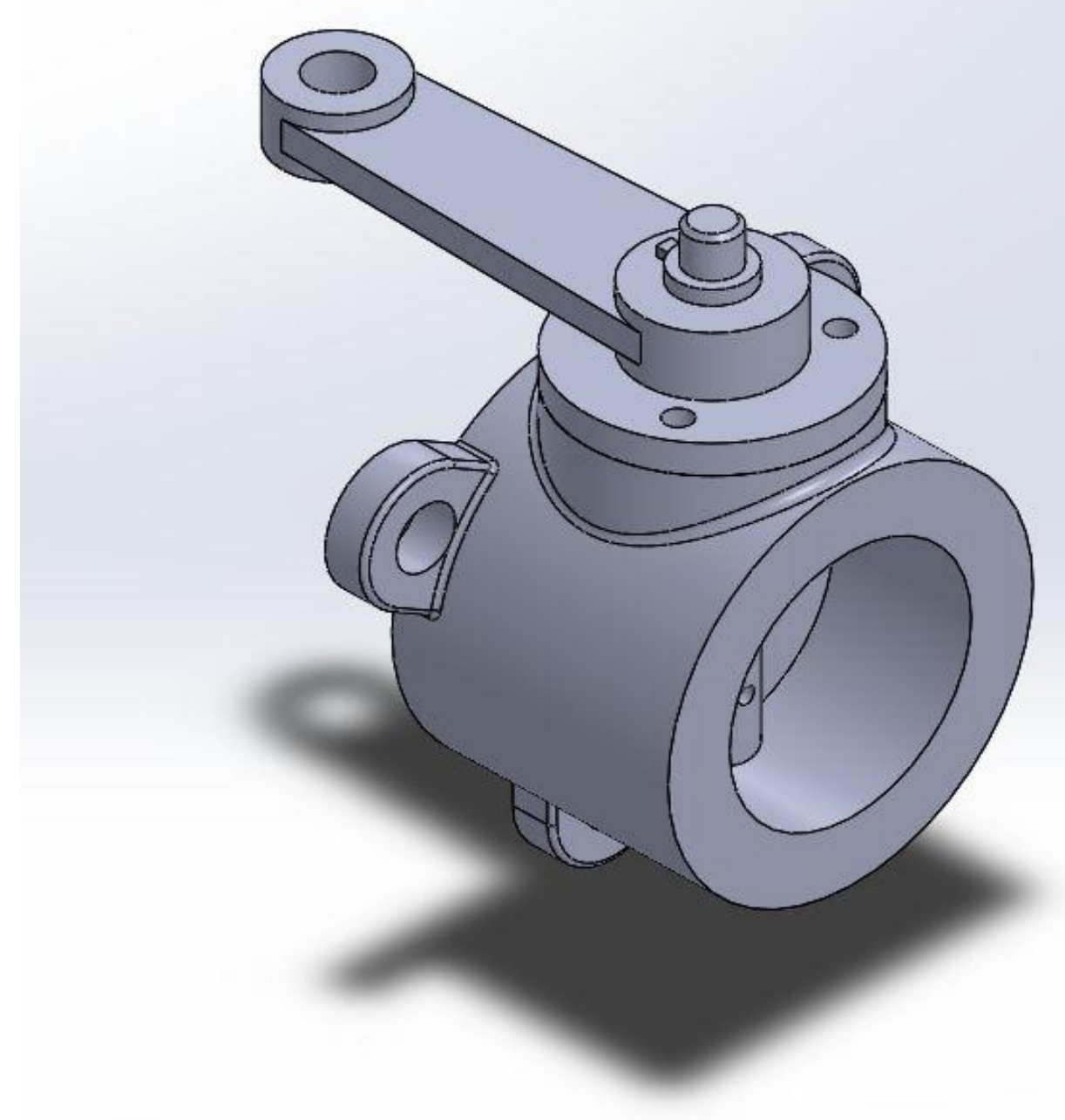

Figure 3 - One of several assembly exercises used to assess students in their assembly skills and knowledge, at the end of the year.

The game was conducted as part of the timetabled practical computer laboratory based sessions. Six groups of students took part in the GBL activity. The average size of the group was 15 . The game was conducted as designed and under close supervision in order to ensure that rules and guidelines were adhered to. Both hands-on and simulated computer-based activities of the game were performed. The students were rewarded in accordance to their ranking position.

On presentation of the overall results in performance and allocation of prizes for the three top finishers, participants were given a questionnaire to complete and return. The questions were intended to establish whether certain research questions and 
objectives were addressed in running the event. The questions therefore addressed aspects such as fun, collaboration, self-assessment in performance, absorbency during the tasks, learning by doing etc. The results from more than fifty questionnaires was to provide qualitative feedback and results.

Quantitative results could therefore be established through records and monitoring performance at a later date, post gaming event. The use of this information was used as indicated in chart 11 . This chart tracks the tariff points at entry to HE for both control and experimental groups and indicates differences in performance, with and without exposure to the gaming event. The researches were also interested in the type of educational background in which the tariff points were earned (National Vocational Qualifications or General Certificate of Secondary Education qualifications). This is further discussed under section 5 where the research questions are addressed.

\section{Summary of findings, analysis and conclusions from feedback questionnaires}

A total of 55 questionnaires were returned by students that participated in the experimental assembly game. This was a good response rate which could later allow comparison with the control group, who did not participate. The purpose of the questionnaire was to determine the effectiveness of the gamification event, as perceived by the students and to verify this as part of on-going research. At the core of the questionnaire were questions intended to establish whether the activity had met with Gagne's defined nine elements of instruction [Gagne, Briggs \& Wagner, 1992] which serve as a useful guide, to this day. The nine events are as listed in table 3 below. These are also as discussed and applied by Becker K, 2005 and Becker K 2010.

Table 3 - A List of Gagne's Nine Events interpreted through Game Design

\begin{tabular}{|l|l|}
\hline 1. Gaining Attention (Reception) \\
\hline 2. Informing Learners of the Objective (Expectancy) \\
\hline 3. Stimulation Recall of Prior Learning (Retrieval) \\
\hline 4. Presenting the Stimulus (Selective Perception) \\
\hline 5. Providing Learning Guidance (Semantic Encoding) \\
\hline 6. Eliciting Performance (Responding) \\
\hline 7. Providing Feedback (Reinforcement) \\
\hline
\end{tabular}




\section{Assessing Performance (Retrieval) \\ 9. Enhancing Retention and Transfer (Generalization)}

The nine events can be embodied, directly or indirectly, to game elements. They are widely used as a benchmark for evaluating educational games [Becker K. 2006].

Once the responses are analyzed, comments and conclusions for future will be made that will assist in improvements in the development of future work.

Essential elements of educational gaming must include fun and engagement by the learner and these can be in jeopardy if designed by the educator alone without reference to them. According to Hirumi and Stapleton (2010), games that overemphasize educational requirements often fall short of realising the potential of play, game and story for creating memorable experiences.

\subsection{Responses to activity questionnaire}

Question 1 (see chart 1) addressed the matter of whether participants had thought that they had applied skills and knowledge gained during the weeks leading to the game and whether the skills were further enforced during the activity. A statement was given to determine whether they agreed or disagreed along with the option of commenting. Comments were of value to the authors as they provided a valuable means of described views from the participants. $96 \%$ of respondents agreed that they had applied skills and knowledge that was further underpinned, whilst $4 \%$ disagreed.

Most comments had indicated that the anticipation of the event had incentivised preparation by practice, something that wouldn't otherwise had normally been done (except perhaps in preparation for an examination as oppose to a gaming event). One able student considered the event to have become tedious after a while, something that wasn't reflected in the comments of others. This would indicate that the event utilised skills at a level that was within the proficiency of most.

Question 2 (see chart 2) was intended at establishing whether the game was fun to participate in whilst simultaneously offering an element of competition against peers within an Activity Based Learning environment. Fun is associated with play and is considered to be the optimal life experience which triggers the flow phenomenon 
(Csikszentmihalyi, 1990, 1996) and is most aligned with theories of intrinsic motivation [Deci \& Ryan, 1985; Lepper, Keavney \& Drake, 1996]. Flow theory is defined by Csikszentmihalyi as an optimal life experience in which people are so absorbed and engaged by the experience of activity that time appears to diminish or vanish. In adults this typically reported whilst experiencing leisure related activities such as gardening or woodworking (though any activity can produce it). Flow theory includes the following components:

- Optimal challenge

- Completely attention absorbing

- Contains clear goals and provides clear feedback on whether the goals are being met

- Sufficiently absorbing to free the participant of other worries

- Feelings of self-consciousness are alleviated

- Total control in the activity

- Time does not seem to exist

Engineering is a vocational subject typically studied by learners who are practical problem solvers. There is therefore a strong case for a significant proportion of learning activities in encompass flow theory [Gupta S Madhu, 2008 and Euchner, J 2014]. $98 \%$ of respondents agreed that it was whilst only $2 \%$ disagreed. It is anticipated that few respondents who disagreed were the least prepared. General comments included 'enjoyable' whilst also 'very competitive'.

Question 3 (see chart 3) focused on the collaborative aspects of learning and whether it had helped participants in the activity. Pairing of participants was a random process rather than matching by set criteria. This was intentional in order to establish the response to this. Collaboration was required for both mechanical and physical assembly using a mix of verbal communication as well as practical skills (by applying logic and psychomotor ability). It was regarded as an important aspect of the game [Romero M, 2012, Nelson 1999] along with the social aspect. Collaboration also fostered a situated learning by doing approach [Van Eck R 2006]. 95\% of respondents had agreed that collaboration was applied but the extent differed when compared to competing teams. $5 \%$ disagreed in that they considered collaboration to have been ineffective. The key reasons that was identified was due to 
'Lack of contribution by partner due to variability in ability'.

Most comments regarding collaboration were positive:

'Communicated well'

'If the task was known in advance we would have communicated a better strategy for solving the puzzle'

'good game for teamwork' and

'we communicated and adapted our solving technique for the challenge'.

Question 4 (see chart 4) was intended to establish the proportion of participants that had considered the gaming event as an opportunity to gauge their own standard against that of their peers, thus providing a means of formative self-assessment. Although $87 \%$ agreed that it had, 13\% disagreed and claimed that it hadn't. This was anticipated as performance was often governed by how well standards of pairs were matched (an aspect that was left to chance, deliberately, so that weaker students could be assisted by their peer).

Question 5 (see chart 5) required feedback for establishing whether the activity was a welcome change to the usual and 'traditional' CAD practical sessions. 95\% agreed that it was and feedback comments indicate a strong agreement with this. Words used to respond to this question included:

'Great hands-on learning', 'fun and different', 'A good occasional alternative', 'different and interesting', 'engaging', 'much more fan than usual lesson', 'nice change from usual and the music helped', 'fun at start gradually becoming more challenging', 'more sessions like this....appreciated'

Only $5 \%$ did not consider the event to be a refreshing change.

Question 6 (see chart 6) was intended to establish whether students considered whether the physical build that preceded the CAD build had made the CAD build process easier. As was anticipated, unless the participant already had sufficient proficiency in using the software, the mechanical build was of little help. $62 \%$ of respondents said that it helped but the comments clarified the justification for the 
responses. 5\% disagreed in that they didn't think that the mechanical build had helped and $33 \%$ said it partly helped. Where the mechanical build had helped was in the association of colour with each piece and order of sequence and position in the build. The colours and physical pieces therefore appeared to have helped more than hindered in establishing a logical building process and memorizing the process with aid of the colours.

Question 7 (see chart 7) required feedback on collaborative working with a peer. As collaborative pairs were selected at random, effective collaboration depended on how well balanced in proficiency and aptitude the pair were. In cases where there was an imbalance it was expected that the stronger member would take the lead and the weaker member would benefit by learning from the stronger member. Although this was often the case, there was also the risk of resentment due to weakening the team and scoring lower in the overall rankings. $60 \%$ had claimed that it was helpful working with a peer (though a proportion of these respondents may have come from the weaker member who benefitted from working with a more able and proficient partner). $18 \%$ had responded negatively to claim that it was not helpful to them having a partner for the activity and $22 \%$ claimed that it was only partly helpful. The response score may indicate to us that weaker learners had benefited from coworking and had responded positively. The more proficient students who were partnered with a weaker member may have responded negatively or to this question. Well matched pairs who collaborated well would also have answered positively.

Question 8 (see chart 8) asked participants whether, in their opinion, there should be more activity based learning sessions during class. $87 \%$ of respondents responded positively with 'YES', $9 \%$ said 'NO' and $4 \%$ were indifferent. The consensus was therefore in favour of more $A B L$.

Question 9 (see chart 9) asked whether the activity helped develop skills in the software. The anticipated response was that it would not as that was not an objective of the activity. To reinforce existing knowledge, raise self-awareness in proficiency and have fun in the process were part of the objective, yet $64 \%$ of respondents thought that the activity had helped them develop, 35\% did not and 1\% was indifferent. 
Question 10 (see chart 10) sought to establish whether most students thought that the activity was interesting and relevant to their course. The majority (82\%) thought that it was whilst $4 \%$ thought that it was not and $14 \%$ were indifferent. 

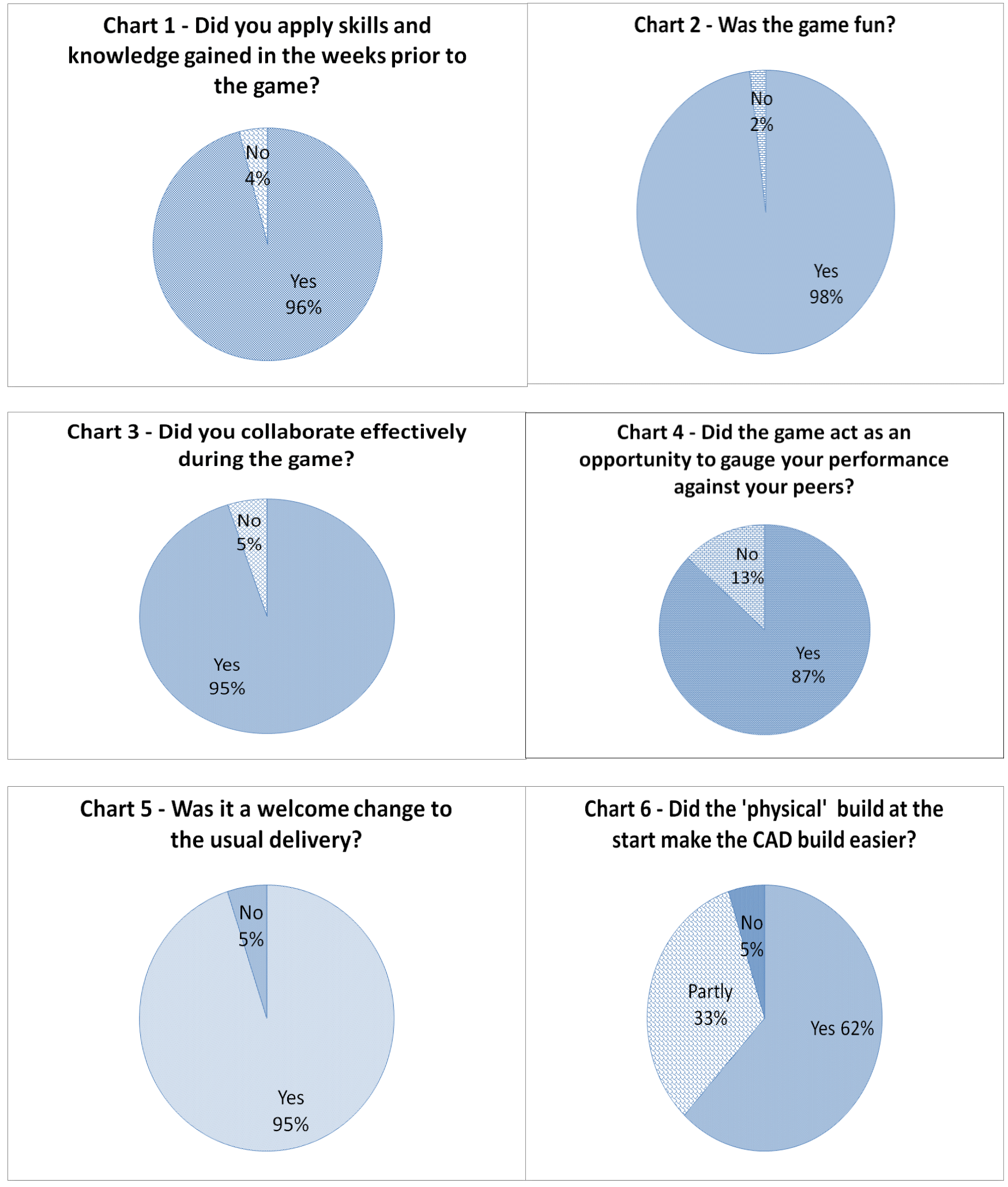
Chart 7 - Was it helpful working with a peer?

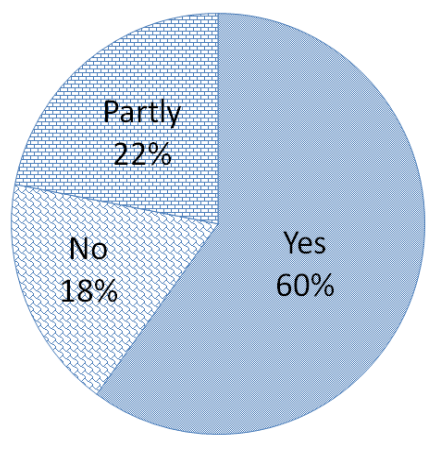

Chart 9 - Did the activity help you develop your skills in the Software application?

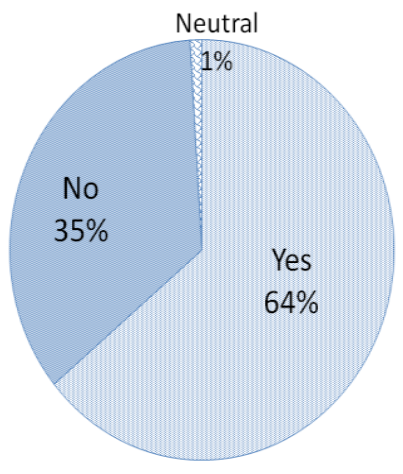

Chart 8 - Do you think more classroom sessions should be activity based?

Neutral

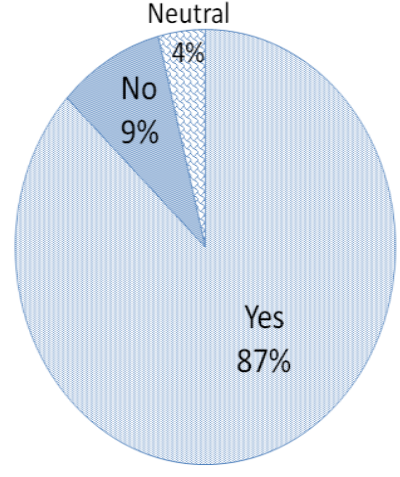

Chart $10-$ Was the activity interesting and relevant to your course?

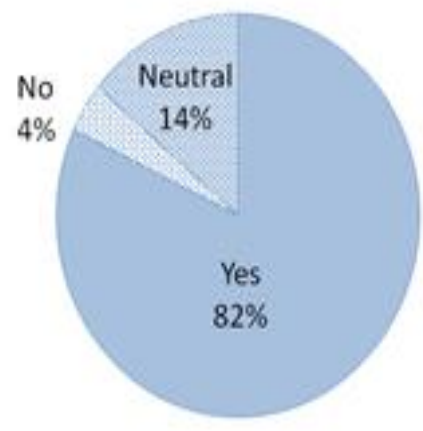




\section{Addressing the research questions}

The key questions to be addressed in this research are:

- Is there a correlation between the students who performed in the higher finishing positions at the end of the gamification event and their end of year assessment element in assembly?

The higher finishing position students are classed as those who scored high enough to finish within a gold, silver or bronze position within each set of students. The game was repeated for a total of six sets of students (separate tutorial groups). 80 students had taken part in the game of which 37 had been classed in either a gold, silver or bronze finishing position. We are therefore able to compare the 37 top finishers with the remainder 43 who either completed but ranked below the top finishers of gold, silver or bronze or failed to complete altogether (as indicated by DNF on the score of results).

The 37 top classed finishers had achieved an overall score of $76.7 \%$ in the end of year assessment exercise. This compared to $74 \%$ for the lower ranking students, which is not significantly different.

- How did the 75 absent students perform in their end of year assessment element in assembly compared with the 80 students who took part in the gamification event?

These 75 students are classed as one of our control group in this research. We can determine whether, overall, they had performed better, worse or no different to our experimental group and to what extent. The other control group were the students of 2015/16 who had not taken part in the game but assessed in exactly the same method at the end of year.

The students who did not take part in the game scored an average of $67.8 \%$ in the end of year assessment as compared to $74 \%$ for all game participants $(6.2 \%$ average difference in assessment score) 
- Did the students who performed in the higher finishing positions enter Higher Education with a greater number of tariff points compared to the lower finishing and non-completing students?

We are able to track the entry qualifications of all the participating students and hence make a comparison of the tariff points at entry into Higher Education between the top and lower finishing students. Tariff points are associated with the level of qualification at entry. The higher the grades, say at GCSE (General Certificate of Secondary Education) Advanced Level subjects, the higher the tariff points. Most qualifications, including National GNVQ (General Non-Vocational Qualifications) have an associated tariff weighting. Some qualifications such the Access into Higher Education completing certificate and the School's own Engineering Foundation Course don't have associated tariff points. Such courses have been established to assist either mature students or students with qualification unrelated to Science and Engineering, in order to gain entry on to Science, Technology and Engineering degree courses. School Leaving Diplomas within an International market of undergraduate recruitment don't have tariff points associated with them. It is of interest to establish whether students with unquantified tariff points at entry to Higher Education performed better or worse within the main cohort.

The average tariff points at entry to Higher Education for the top classed finishers was 293 points whilst for the remainder participating students this was 272 . The difference in tariff points is not significant when you consider a grade $A$ at Advanced Level GCSE (General Certificate of Secondary Education) carries 120 tariff points.

\section{- How did the year group perform in comparison to the previous year's} group?

As this was the first year that the gamification activity was introduced, we wish to establish whether the year group had overall performed better than that of the previous year. However, as the previous year's cohort had not been introduced to the gamification activity, we may consider them as another control group of greater size. We shall then be able to compare their end of year assessment score average in the element of assembly with that of the students who took part in the gaming activity. A comparison between the overall tariff points average at entry will also be necessary.

The average score in assessment for all game participants was $74 \%$ whilst for the same assessment, during the previous year, the average score was $67.8 \%$. This 
indicates a marked improvement of 6.2\%. Zero scores and non-submit (NS) students have been excluded in the calculation of scores. However, it was observed that in a cohort of 157 students during 15/16 there were 15 non-scoring, NS students, 4 more than for the same size year group during 16/17, when the gaming event was introduced as part of teaching and learning activities. This indicated a correlation between performances and participation in the game based activities and overall coursework attainment.

Impact on overall assignment score with reference to assembly game participation

The assembly element of assessment formed only a part of the overall assessment but as a result of its introduction the overall assessment score was raised from $61.5 \%$ in the previous year to $65.8 \%$. The reduction in NS students was confined to the assembly element of assessment. Students in the previous year (15/16) had an overall higher average of tariff points at entry to HE (288 compared to 272 for the $16 / 17$ cohort). Despite the lower entry level to HE, the students exposed to the gaming activity had scored better in assessment than the students in 16/17 game participation activity.

\subsection{Entry tariff and performance}

It was almost inevitable that the 37 top performing students (classed as gold, silver and bronze positions) would be the students with the largest average of tariff points at entry to $\mathrm{HE}$. This was verified (293 compared to 272 ) even though not significant.

Our interest lay in the tariff points of DNF (Did Not Finish) game participants. These were students who did not manage to complete the game in the allocated time. Half $(50 \%)$ of these students did not have any tariff points at entry to HE as they were admitted on a 1 year Foundation Course prior to undergraduate studies. The remainder 50\% had entered HE with 205 tariff points which was significantly lower than (by $30 \%$ ) as compared to the 37 top performing students.

We were also interested in the range of entry qualifications that attributed to the tariff points of the top performing students. These were primarily made up by GCSE A'levels and Engineering specific level 3 qualifications (what are commonly known in the UK as BTEC awards-awarded by the Business and Technology Education Council). The lower performing students had a mixture of level 3 subjects but not engineering specific (such as ICT or Applied Sciences), foundation studies or a 
Certificate in Higher Education (CHE). The $\mathrm{CHE}$ is awarded on the basis of completing part of course at another HE. This would imply that the less performing students had set out in embarking on an engineering undergraduate course without the same conviction and focus as the better performing students. Improvement in performance was however achieved by introduction to the gaming activity in teaching and learning for all students.

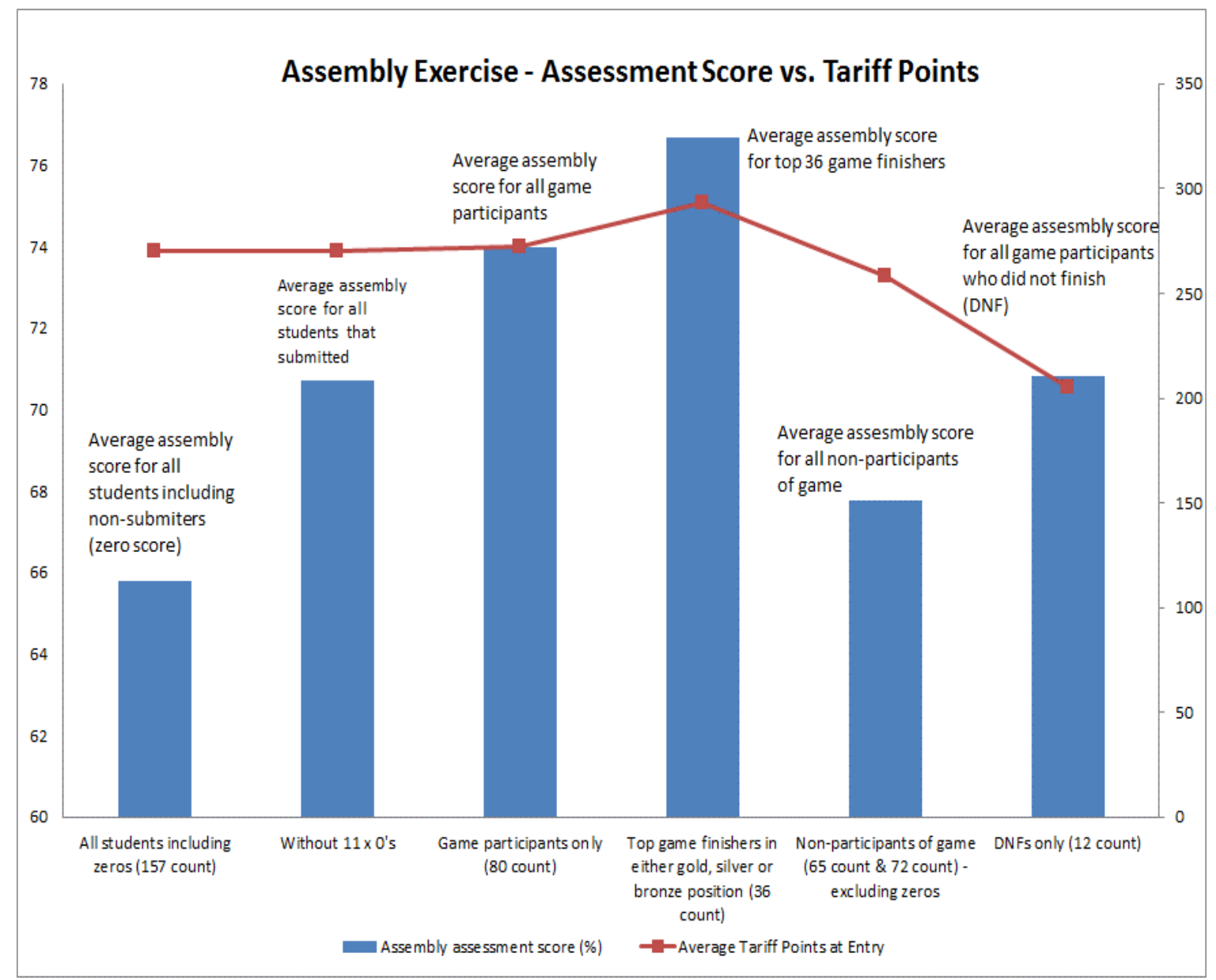

Chart 11 - Graphical representation of results showing improved overall performance by game participants and the student profiles in average tariff points at entry in to Higher Education. The red line represents the tariff points at entry of classified groups of students (participants, non-participants, non-completers). The vertical scale to the right indicates average tariff points at entry whilst the vertical scale to the left represents end of year assessment score in subject matter.

\section{Conclusions}


We can safely conclude that the gaming activity was a success on the basis of having benchmarked it against Gagne's defined nine elements of instruction [Gagne, Briggs \& Wagner, 1992]. The nine events were listed in table 1.

The qualitative results were overall very positive as is indicated from student feedback and reported in the charts (1 to 10) along with the discussion accompanying these charts.

The quantitative benefits of the activity overwhelmingly support further activity based learning $(A B L)$ and, in particular, gamification $(G B L)$ events in the teaching and learning process. Testimony to this are the results illustrated in chart 11 which show overall improvement in assessment results regardless of student academic level of achievement, as quantified in tariff points, at the point of entry into Higher Education.

\section{Future work}

The activity will be incorporated as part of future delivery as part of the undergraduate courses and reviewed for improvement on an ongoing basis. Based on the comments made by a number learners a similar activity will be devised in which a mechanical assembly is used as an alternative to the resin puzzle. This would further help introduce principles of mechanical engineering design. Future games will be designed to include aspects such as application of mechanical elements (i.e. bearings, springs, fasteners) and tolerances (limits of fits). These may be incorporated as part of the activity's learning outcomes. In addition to the investigation of GBL in higher education the authors are considering extending the study to secondary education environment as part of the STEM initiative.

\section{Acknowledgements}

The authors wish to thank Lindsey Botha, data analyst, School of Computing and Engineering, University of Huddersfield for her support in the supply and analysis of student data.

Thanks also to Proto labs (www.protomold.eu/parts) for their supply of the resin cube puzzles used as part of the GBL activity. 


\section{References}

1. Aamodt, A. \& Plaza, E. (1994). Case-Based Reasoning: Foundational Issues, Methodological Variations, and Systems Approaches. Artificial Intelligence Communications, 7(1), pp39-59

2. Becker K, (2010). Video Game Pedagogy: Good Games=Good Pedagogy. In Christopher Thomas Miller (Ed), Games: Purpose and Potential in Education (pp 73125).Springer, NY 2010 ISBN: 978-1-4419-3533-5

3. Becker K, How are Games Educational? Learning Theories Embodied in Games. Paper presented at the DiGRA 2005 2nd International Conference, "Changing Views: Worlds in Play", Vancouver, B.C., June 16-20, 2005

4. Becker k., (2007). Digital game-based learning once removed: Teaching teachers. British Journal of Educational Technology Vol 38 No 32007 pp578-488

5. Blake, J (1999). Computer-based learning: Games as an instructional strategy. The ABNF journal, volume 10, issue 2, March-April10(2):43-6 1999

6. Blake, J., \& Goodman, J. (1999). Computer-based learning: Games as an instructional strategy. The Association of Black Nursing Faculty Journal, 10(2), 43-46

7. Bloom, B.S. (1964). Taxonomy of Educational Objectives; the classification of educational goals, by a committee of educational examiners. New York: D. MacKay

8. Csikszentmihalyi, M. (1990). Flow: The psychology of optimal experience. New York: Harper \& Row

9. Csikszentmihalyi, M. (1996). Creativity: Flow and the psychology of discovery and invention. New York: Harper Collins

10. Deci, E.L., \& Ryan, R.M. (1985). Intrinsic motivation and self-determination in human behaviour. New York: Plenum Press

11. Dempsey, J, Lucassen, B., Gilley, W., \& Rasmussen, K. (1993-1994). Since Malone's theory of intrinsically motivating instruction: What's the score in the gaming literature? Journal of Educational Technology Systems, 22(2), 173-183

12. Demsey, J.V., Lucassen, B.A., Haynes, L.L., \& Casey, M.S., (1996).

Instructional applications of computer games. New York, NY: Annual Meeting of the American Educational applications of computer games. New York, NY:Annual Meeting of the American Educational Research Association. (ERIC Document Reproduction Service No. ED 394 500)

13. Driscoll, M. P. (1994). Psychology of learning for instruction. Needham Heights, MA: Paramount Publishing, Inc

14. Euchner, J (2014). The Future of Engineering Education. Research Technology Management, 57(1) 15-19

15. Gagne, R.M., Briggs, L.J., \& Wagner, W.W. (1992). Principles of instructional design (4th ed.). Fort Worth, Texas: Harcourt Brace Jovanovich College Publishers 
16. Gupta S Madhu, Learning methods of problem solving, IEEE microwave magazine, p134-165, October 2008

17. Hirumi, A. and Stapleton, C., (2010). Applying Pedagogy during Game Development to Enhance Game-Based Learning. In Christopher Thomas Miller (Ed), Games: Purpose and Potential in Education (pp 127-162).Springer, NY 2010 ISBN: 978-1-4419-3533-5

18. Hamari J, Koivisto J and Sarsa H. Does gamification work? - a literature review of empirical studies on gamification, In IEEE $47^{\text {th }}$ Hawaii International Conference on Systems (HICSS), Waikoloa, HI, USA:IEEE, 2014, pp.3025-3034

19. Jonassen D. (1999). Designing constructivist learning environments. In C.M. Reigeluth (Ed.), Instructional Design Theories and Models: A New Paradigm of Instructional Theory (pp. 215-239). Hillsdale, N.J.: Lawrence Erlbaum Associates

20. Kim S. Effects of the gamified class in engineering education environments. Journal of Convergence Information Technology (JCIT) 2013; 8:253-260

21. Lepper, M. R., Keavney, M., \& Drake, M. (1996). Intrinsic motivation and extrinsic rewards: A commentary on cameron and pierce's meta-analysis. Review of Educational Research, 66(1), 5-32. doi:10.2307/1170723

22. Markopoulos A.P., Fragkou A., Kasidiaris P.D., and Davim J.P. Gamification in Engineering education and professional training. International Journal of Mechanical Engineering Education 2015, Vol. 43(2) 118-131

23. Nelson, L., (1999). Collaborative Problem-Solving. In C.M. Reigeluth (Ed.) Instructiona Design Theories and Models: A New Paradigm of Instructional Theory (pp. 241-267). Hillsdale, N.J.: Lawrence Erlbaum Associates

24. Romero, M. Usart, M. Ott, J. Earp, S. de Freitas, S. Arnab, (2012). Learning through playing for or against each other? Promoting Collaborative Learning In Digital Games Based Learning. Proceedings of the ECIS conference, Barcelona June 2012

25. Schank, R.C., Berman, T.R., \& Macpherson, K.A. (1999). Learning by doing. In C.M. Reigeluth (Ed). Instructional Design Theories and Models: A New Paradigm of Instructional Theory (pp 161-179). Hillsdale, N.J.: Lawrence Erlbaum Associates

26. Seaborn $\mathrm{K}$ and Fels DI. Gamification in theory and action: a survey. Int $\mathrm{J}$ Human-Comput Stud 2015; 74: 14-31

27. Stapleton, C.B., \& and Hughes, C.E. (2006). Believing is seeing: Cultivating radical media innovations. Computer Graphics and Applications. 26(1), 88-93

28. Van Eck, R. (2006). Digital game-based learning: it's not just the digital natives who are restless, EDUCAUSE Rev. 41 (2) 